\title{
Editorials
}

\section{Warm up}

Missing teeth may have been macho in the past, but surely the toothless grin of the prop forward should only be seen in the history books. Mouth guards are easily available and we probably all agree that they should be worn by those at risk. How much do we really know about their quality? Greasley and Karet give us a timely reminder about the need for appropriate functional assessment and quality control (p 31). But, trauma is not the only way to lose our teeth and it seems that there might be another link between dental injury and sport. We constantly emphasise the importance of fluid replacement; advice that features very strongly in our Olympic review, but few of us would think of the effect that sports drinks may have on our teeth. Many of the drinks tested by Milosevic have erosive potential, and he also points out that frequent intake of sugary drinks by constant sipping could be even more harmful ( $\mathrm{p} 28$ ).

Remember the Olympics? So far in the past and so far in the future. There was much soul searching on the team's return from Atlanta, but lessons are often best learnt after the initial excitement has settled. We now have the opportunity to review the reports of the medical team. There are examples of good practice but also lessons to be learnt and suggestions for the future. We hope, by publication of these reports, to ensure that future team personnel learn from the experience of Atlanta. The next major multisport games will be the Commonwealth Games in Kuala Lumpur and medical teams are starting to organise already in many countries. These Olympic reports are as much for the future as about the past ( $p 76$ ).

Ankles injuries will always feature in sport and Renström and Konradsen provide a scholarly update on an old subject ( $p$ 11). Taunton addresses a new concept: exercise for the older woman (p 5). Hall throws down a challenge about our management of diabetes ( $p 3$ ), while Brukner and Bennell give us the antipodean line on injury (p 2). Bottomley was the author of one of the great recent successes of British sports medicine, the distance learning course from Bath (p 3). While tucked away in the back of the journal is a book review of the Scottish Sports Injury Clinics Report ( $p$ 85). We will hear more of this in future issues.

\section{Will money corrupt sports medicine?}

Few people become wealthy through sports medicine. Most of us wonder if there will ever be any money! But that day is not so far away. The changing climate in sport has also changed the professional relationship between doctors and players. Most of us became involved through our love of sport and were always happy to help out when needed. We enjoyed our sport and our sports medicine and, although we were not paid, we still worked to the highest professional standards. Our only reward, if we were lucky, was an invite to the annual dinner or an occasional ticket to the big event. Sport was for fun and we all mucked in for the good of the club. Times have changed. Television has made professional sport very wealthy, erstwhile amateur sports are now professional, and even peripheral minority sports attract such valuable sponsorship that athletes train full time. There is now almost no perceptible difference between the amateur and the professional player. This revolution has not yet reached the medical team. We still turn up at the game but while we still provide our services free, the players we treat could now be earning vast sums.

In the past doctors have been reluctant to talk money, but changes in the National Health Service in the United Kingdom have made us all very aware of costs, contracts, and the value of medical time. It is unlikely that we shall continue to give our services free or for token reward, especially to wealthy clubs with highly paid players. There is also a new found confidence in those who have undergone special training, taken postgraduate exams, and consider themselves specialists. In this environment the current relationship between sport and medicine will probably evolve into a formal commercial partnership. Doctors will negotiate a fee, enter into a contract, and receive an appropriate salary. A fairy tale come true perhaps, but will everyone be happy?

Money carries responsibilities. In this contractual relationship the doctor is the employee and answerable to the manager or chief executive of the club or organisation. There will be pressure to respond to the demands of management. In the United Kingdom, general practitioners are independent contractors and unfamiliar with the employer-employee relationship. Hospital doctors are employees, but work for organisations that are usually sympathetic to the health care ethos. Sport is an entirely different business and sporting organisations are neither health care providers nor charitable institutions. They are entirely outcome driven or, to borrow a cliché, are only as good as their last result. In this highly competitive sporting market doctors may find their professional independence threatened by pressures to treat, rehabilitate, inject, or operate in a manner that they find unacceptable. They may be asked to administer training aids with which they do not agree or to allow a player to return to play sooner than they wish. Indeed, at times, the patient supported by the organisation may demand intervention that the doctor believes is in conflict with professional standards or ethics. As an employee the doctor's responsibility will be to the organisation. In the harsh business world of top sport, contracts may be short and depend on performance and compliance with company policy.

Sporting doctors may in the future earn money from sport, but at a price. Could that price be their personal and professional integrity? 